\title{
In search of evidence for the hue-heat hypothesis in the aircraft cabin
}

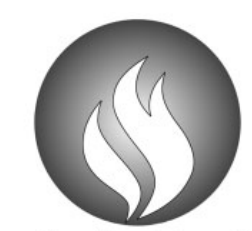

The Society of Light and Lighting

\author{
F Albers PhD, J Maier PhD and C Marggraf-Micheel PhD \\ German Aerospace Center, Aviation and Space Psychology, Hamburg, \\ Germany
}

Received 17 January 2014; Revised 18 June 2014; Accepted 12 July 2014

\begin{abstract}
This paper examines whether the use of coloured light can influence aircraft passengers' temperature sensations and can make the climate be perceived as cooler or warmer ('hue-heat hypothesis'), a phenomenon shown in earlier light laboratory experiments. Experiments with 199 subjects were conducted under realistic conditions, a cabin of a single-aisle aircraft. Two lighting scenarios (yellow and blue) were combined with different temperatures. Results show an effect in the hypothesized direction. The impact of lighting colour on climate perception and evaluation can be observed in the whole sample and in certain subgroups of subjects. The size of the effect agrees with former studies. A largescale application of this effect in the aircraft/aviation industry could lead to energy savings and contribute to cost effectiveness.
\end{abstract}

\section{Introduction}

A considerable amount of research in the fields of experimental psychology, applied psychology and psychological ergonomics has been done about the possible influence of colours or coloured surfaces on thermal sensation and thermal comfort. This research, which may be referred to as testing the 'hueheat-hypothesis', mainly took place between the 1960s and late 1980s (see Heijs and Stringer ${ }^{1}$ for a comprehensive review). The 'hue-heat hypothesis' claims that a cool ambient colour leads to a cooler temperature perception and that a warm ambient colour leads to a warmer temperature perception. The basic aim of this work from the beginning was the possible contribution to energy saving by applying such an effect to industrial and everyday activities. Energy saving and energy efficiency is nowadays a widespread motivation for doing research because of the

Address for correspondence: Frank Albers, German Aerospace Center, Sportallee 54a, 22335 Hamburg, Germany.

E-mail: frank.albers@dlr.de importance of environmental impacts, protection of energy resources and cost control in virtually every industry, especially in the energy-hungry aviation business. ${ }^{2,3}$

The results of the above-mentioned research on the thermal effects of colours in the 20th century were quite disappointing from the researcher's point of view: Either no effects of colour on temperature perception were found ${ }^{4,5}$ or the observed effects were very small and at that time were of no practical significance. ${ }^{6}$ For example, Fanger et al. ${ }^{6}$ showed a difference in temperature sensations of $0.4^{\circ} \mathrm{C}$ depending on the illumination of a room by either blue or red light.

Some aspects, besides the methodological criticism which might justify new experiments in this field on its own (e.g. use of very small sample sizes, cf. Heijs and Stringer ${ }^{1}$ ), made it worthwhile for us to conduct new studies in the field of applied psychology according to the 'hue-heat hypothesis'. First, and above all, a lot of energy is consumed in the aviation industry and energy costs are a very 
important cost factor for airlines, a fact that also leads to a more sophisticated design of energy-efficient engines. For example, fuel consumption of turbojet engines has been reduced by approximately $50 \%$ since the 1950 s. $^{7,8}$ If an impact of lighting on temperature and comfort sensation can be found, even a small effect - if systematically applied - could have a measurable impact on energy consumption and costs. Second, if an effect of ambient colour on thermal comfort exists it could easily be induced because nowadays aircraft are (or can be) equipped with LED lighting systems, which allow the creation of various lighting situations. Third, preliminary research showed that one could be quite optimistic of the validity of the "hue-heathypothesis' in applied cabin environments. ${ }^{9}$ Finally, we are also very interested in maintaining and even raising the level of the perceived comfort: We think that proper climate control and certain ambient lighting situations, established by state-of-the-art LED techniques can enhance passengers' comfort in the aircraft cabin.

Of course, our research was also theoretically driven. To define comfort we used an approach which is in accordance with the relevant psychological and ergonomic literature. The passengers' comfort is a function of subjective well-being, ${ }^{10}$ which is influenced by multiple objective environmental factors. ${ }^{11,12}$ According to the specific situation in an aircraft cabin, a comfort model was formulated which includes a variety of objective factors (temperature, air-velocity, humidity, etc.) with their effects on passengers' subjective thermal comfort. This model and details have been published in Winzen et al. ${ }^{9}$ and Marggraf-Micheel et al. ${ }^{13}$ From a more theoretical perspective, the testing of the 'hueheat hypothesis' means to examine whether the objective factor, lighting, with its direct or indirect influence on perceived comfort, has to be considered in models of passengers' thermal comfort.
These practical and theoretical aspects taken together led to the idea of testing the 'hue-heat-hypothesis' in a realistic aviation environment, a cabin mock-up of a singleaisle aircraft, with a reasonably large sample of subjects. We wanted to test the influence of coloured ambient lighting on passengers' thermal perceptions and their well-being and thus thermal comfort. If there is a positive outcome this could have interesting theoretical and practical implications: Coloured light could be used in energy- and cost-saving applications in the aviation industry and, on the other hand, this would mean that the lighting situation is an environmental factor that has to be considered in passengers' (thermal) comfort models.

\section{Method}

\subsection{Participants}

The experiments conducted for this study involved a sample of altogether 199 subjects with normal colour vision. In each experimental session 50 subjects took part (session one comprised 49 due to organizational reasons). The mean age in the whole sample was $M=32.6$ years $(S D=10.8)$, the age range was between 18 and 55 . The sex ratio was 50:50 in the whole sample as well as in each of the four experimental sessions. A prerequisite for the participation in the study was a school graduation qualifying to study at a German university (German 'Abitur'). Subjects were paid $€ 60$ each for their participation.

\subsection{Instruments}

2.2.1. Cabin mock-up

All experiments were conducted in the single-aisle aircraft mock-up Dornier Do728, which is located in a hangar at the DLR Institute of Aerodynamics and Flow Technology in Göttingen, Germany (Figure 1).

This aircraft is a single-aisle jet with a complete cabin interior comprising 70 seats in 14 rows, two seats on the right and three on 
the left side of the cabin. Fifty seats were used for the subjects, four rows were occupied with thermo-dummies equipped with sensors that measure different climate parameters at different locations. The air-conditioning system of the mock-up is fully operational and provides mixed air through 64 inlets that are arranged in two lines along the ceiling and below the overhead bins. After circulation, the air leaves the cabin through 24 air outlets located in the cabin floor. The cabin and climate situation are very realistic and generic for a single-aisle aircraft of comparable size. Only the pressure inside the mock-up cannot be varied and equals ground conditions.

\subsubsection{Climate parameters and climate situations}

For our experiments we wanted to establish different temperatures as independent variables. We aimed at implementing two different temperatures per experimental session which were to be paired with two different

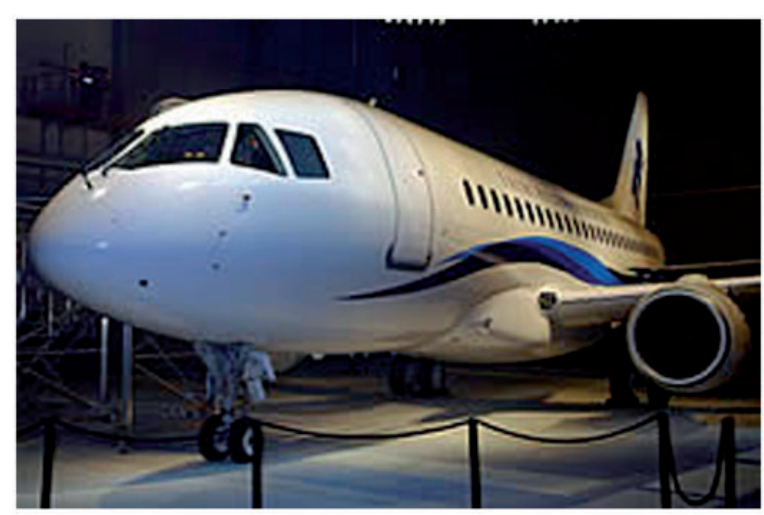

Figure 1 Mock-up Dornier Do728 (CDLR) lighting situations (see Section 2.2.3). Other climate parameters, which might have strong effects on thermal comfort, were to be kept constant. The air velocity was kept steady at values of $0.14-0.16 \mathrm{~m} \mathrm{~s}^{-1}$ and thus far below $0.30 \mathrm{~m} \mathrm{~s}^{-1}$, a comfort-critical value. ${ }^{14}$ The humidity was kept as constant as possible at values below $30 \%$ to establish conditions resembling the situation in real flights. The range of temperatures used is also within the comfort-critical range given by $\mathrm{CEN} .^{14}$ Unfortunately, two climate scenarios could not be stabilized so they could not be used in the analysis of the results. Table 1 shows the temperatures of the six stabilized climate situations that could be used for further analyses and the respective sessions. The temperature values are averaged from all temperature measurement devices inside the mock-up.

\subsubsection{Lighting situations}

The cabin was illuminated by a high-power LED lighting system with two rows of luminaires fixed on either side of the aisle at the level of the overhead bins near the ceiling. Two further rows were fixed on the side panels above the windows, as in a real aircraft (Figure 2).

All given lighting measurements were made with a spectroradiometer (Specbos 1211, spectral range $350-1000 \mathrm{~nm}$ ). Table 2 shows the specifications of the blue and yellow lighting situations. Both the illuminance at the ceiling and the illuminance at the side panels are given. The illuminance on the ceiling was measured at a point on the ceiling's surface approximately $5 \mathrm{~cm}$ next to one of the ceiling luminaires; the illuminance

Table 1 Temperatures of climate situations used for data analysis

\begin{tabular}{lcccccccc}
\hline Experiment no & & 1 & \multicolumn{1}{c}{2} & \multicolumn{2}{c}{3} & 4 \\
\hline Lighting scenario & 1 & 2 & 1 & 2 & 1 & 2 & 1 & 2 \\
\hline Temperature $\left({ }^{\circ} \mathrm{C}\right)$ & 24.3 & $\mathrm{x}$ & 25.4 & $\mathrm{x}$ & 21.5 & 22.5 & 23.6 & 23.1 \\
\hline
\end{tabular}

Note: Temperatures marked with $x$ could not be stabilized and hence data obtained in these parts of the experiment could not be used in the analyses of the results. 


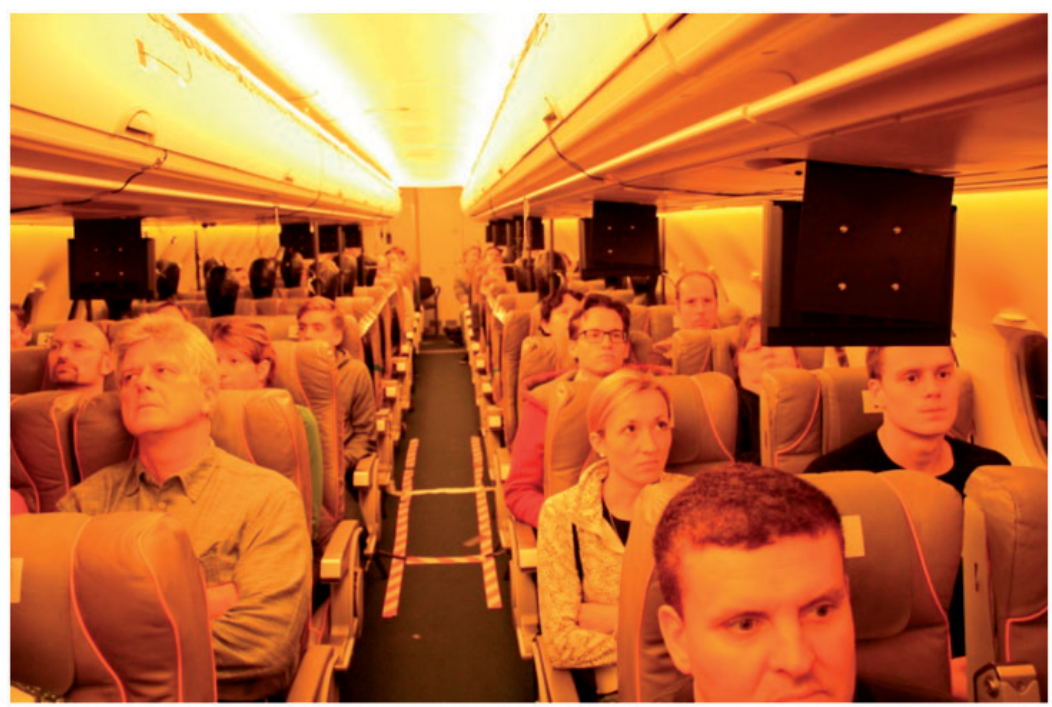

Figure 2 Experimental situation in the cabin mock-up (CDLR)

Table 2 Description of lighting situations

\begin{tabular}{|c|c|c|c|c|c|}
\hline \multirow[b]{2}{*}{ Lighting } & \multirow[b]{2}{*}{$\begin{array}{l}\text { Centroid } \\
\text { wave-length }(\mathrm{nm})\end{array}$} & \multicolumn{2}{|c|}{ Chromaticity coordinates } & \multirow[b]{2}{*}{$\begin{array}{l}\text { Illuminance at } \\
\text { ceiling (lux) }\end{array}$} & \multirow[b]{2}{*}{$\begin{array}{l}\text { Illuminance at } \\
\text { side panel (lux) }\end{array}$} \\
\hline & & $x$ & $y$ & & \\
\hline Blue & 495.9 & 0.184 & 0.240 & 232.1 & 93.8 \\
\hline Yellow & 608.0 & 0.591 & 0.387 & 177.0 & 68.4 \\
\hline Neutral & 520.4 & 0.253 & 0.226 & 290.9 & 114.2 \\
\hline Green & 526.2 & 0.169 & 0.727 & 200.3 & 79.7 \\
\hline Violet & 517.5 & 0.270 & 0.099 & 169.9 & 63.9 \\
\hline
\end{tabular}

on the side panels was measured at a point on the side panel's surface approximately $5 \mathrm{~cm}$ below one of the side-panel luminaires. All measurements were made with the complete lighting system switched on. Figure 2 shows the experimental situation. The specifications of the lighting situations were not changed between experimental sessions and were always the same. In breaks and for short neutralization phases, a neutral lighting scenario was used. Furthermore, a green and a violet hue lighting condition were also used so as to have a broader set of coloured lighting situations that were evaluated by the subjects (all specifications can be seen in Table 2).
The intention was to minimize the likelihood of hypothesis guessing and of behaviours being modified accordingly.

In order to keep the lighting situations consistent and only influenced by the LED lighting system, the hangar in which the mock-up is located was completely darkened so no light could enter through the windows. There were two remaining sources of light inside the cabin: The pocket PCs for the questionnaires (see Section 2.2.4) and the visual entertainment system (see Section 2.3). We consider their influence as rather small compared to the lighting situations established by the lighting system. The 
measured mean illuminances were 0.3 lux for the pocket PCs and 0.4lux for the entertainment system (measurement made at the eye, at viewing distance, with the sensor aimed at the device).

\subsubsection{Questionnaires}

Several variables were measured using questionnaires that were administered on pocket PCs (HP iPAQ214, 400 TFT touch screen display, input by stylus pen).

First, subjects were asked for demographic data. In the repeated parts for the climate/ lighting scenarios, subjects were asked about the effects of the lighting situation including questions about the colour of light, the temperature appearance of the light, its brightness, etc. Furthermore, they were asked about their perception and evaluation of the climate in the aircraft cabin (temperature, air velocity, humidity, etc.). Generally, it was first asked about a parameter's intensity (e.g. 'How intense is the colour's brightness?') on a seven-point rating scale. Then the question followed, to what extent this intensity induces comfort (e.g. 'How comfortable is the colour's brightness?'), which had to be answered on a five-point rating scale. Subjects were also asked to give an estimation of the temperature in degrees Celsius.

Different aspects of psychological and physiological well-being were recorded as well $^{15,16}$ (for details see Winzen et al. ${ }^{9}$ ).

Additionally, participants had to answer questions about more stable preferences and personality traits. Participants had to classify themselves in different groups regarding climate preferences: sensitivity for coldness (high vs. low), sensitivity for heat (high vs. low), sensitivity for air velocity (high vs. low), sensitivity for air quality (high sensitivity for used/stuffy air vs. low sensitivity) and sensitivity for dry air (high vs. low).

Finally, the so-called Big Five personality traits (i.e. Openness to experience, Conscientiousness, Extraversion, Agreeableness and Neuroticism) were assessed once by a wellestablished test called BFI-K. ${ }^{17}$ The whole package of questionnaires is already well evaluated (e.g. Marggraf-Micheel et al. ${ }^{18}$ ) and details of the scales and their measurement reliability can be found in Winzen et al. ${ }^{9}$

\subsection{Design and procedure}

For the data collection in the four experimental sessions, two different climate scenarios were paired with two different lighting scenarios in each session. Whereas the lighting scenarios were the same (blue and yellow) in all experiments, the climate scenarios were different between the sessions to increase the number of obtained data points for climate scenarios (here: temperatures). The two independent variables (climate situation $\times$ lighting situation) established a two-factorial design. For analyses, further inter-person factors were used.

Participants were instructed to wear standardized clothing with long arms and legs and shoes not covering the ankles. The clothing insulation value desired was 1 clo.

The four experiments took place during daytime and normal hours of wakefulness, two of the four experiments started at $10 \mathrm{am}$, the other two at $2 \mathrm{pm}$.

The course of events was the same for all four experiments:

The participants boarded the mock-up and sat down on assigned seats. The assignment of seats took care of an alternation of male and female subjects within every experiment.

Once seated, subjects received a briefing about emergency situations, the handling of the pocket PCs and a rough overview of the course of events. Basically, the procedure in all four experiments was the same, only the sequence of lighting colours and the temperature scenarios was changed between sessions. The procedure can be seen in Figure 3.

The sequence started with a forerun that was needed to establish the first climate scenario. Within this forerun there was a 


\begin{tabular}{|c|c|c|c|c|c|c|c|}
\hline \multicolumn{2}{|c|}{$\begin{array}{c}\text { Stabilization of } \\
\text { climate 1 }\end{array}$} & \multicolumn{2}{|c|}{ Climate / Temperature 1 } & \multicolumn{2}{|c|}{$\begin{array}{c}\text { Changes of } \\
\text { temperature to } \\
\text { climate 2 }\end{array}$} & \multicolumn{2}{c|}{ Climate / Temperature 2 } \\
\hline $\begin{array}{c}\text { neutral } \\
\text { lighting }\end{array}$ & green & yellow & blue & neutral & violet & blue & yellow \\
\hline
\end{tabular}

Figure 3 Example overview of the experimental procedure

lighting situation acting as a red herring regarding the background of the experiment (i.e. green or violet hue); after 10 minutes of this illumination participants worked on the light/climate questionnaires. The briefing and the forerun together took about 1 hour; this made sure that any (differential) effects of different exposures to outside climate conditions which the participants might have had were erased.

Following the forerun, the experimental lighting phases were realized for 10 minutes, and then participants had to work on the questionnaires for approximately 10 minutes under consistent conditions. After one yellow and one blue lighting situation the climate was changed; during this time the participants had a break with snacks, worked on the personality questions and were exposed to another irrelevant lighting scenario (violet or green hue).

The sequence of light scenarios and of temperatures (i.e. warmer climate first vs. cooler climate first) was balanced between the experimental sessions.

During times of exposure to a lighting situation or during waiting periods, subjects were entertained by audio-visual material via the cabin entertainment system. All changes of cabin lighting took place after a phase with neutral light for 1 minute.

One experiment lasted for approximately 3 hours in the cabin for the participants.

With this procedure we established four phases for obtaining dependent variables from the questionnaires under the influence of the independent variables (climate
(Table 1) and lighting situation (blue vs. yellow)).

\section{Results}

Before starting the analyses we examined the data with regard to integrity. We had to exclude the data of three participants from the analyses because they showed consistent patterns of answers that revealed that these subjects either did not take the questionnaires seriously or were not able to work on the questionnaires.

Analysis of the fundamental five personality factors showed that the means of the five factors did not differ between the four experiments, thus it was justified to combine the subjects' data for further analyses.

Results will be reported with regard to the most important dependent variables: The perception of temperature (1: 'very cold' to 7: 'hot'), the evaluation of the degree to which this is comfortable (1: 'very unpleasant' to 5: 'very pleasant'), the subjects' estimation of temperature (in degree Celsius) and the overall satisfaction with the climate (1: 'very dissatisfied' to 5: 'very satisfied').

First, we studied the effects on the whole sample and then we analysed different subgroups.

\subsection{Results for the whole sample}

Figures 4 to 7 show the mean values of the four dependent variables over the different climate situations and lighting situations. The 


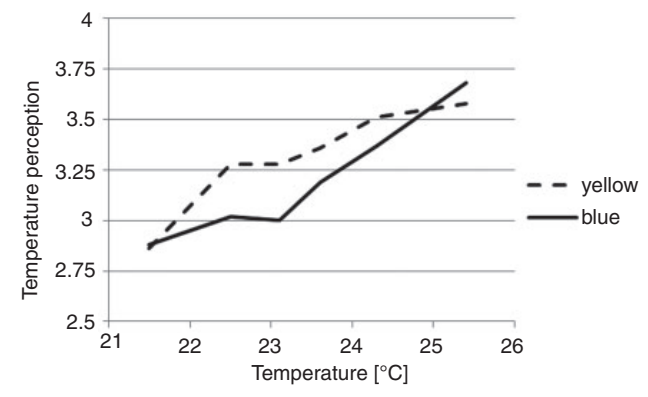

Figure 4 Temperature perception as a function of climate (temperature) under yellow and blue light conditions

results of the analyses of variance (ANOVAs) can be seen in Table 3 .

The results indicate that all means differed significantly. This means that the climate was perceived as warmer and that the temperature was felt more comfortable in yellow lighting. Also, on average, the temperature estimation in degrees Celsius was higher and the overall satisfaction with the climate was higher when the cabin was illuminated in yellow light.

A look at the figures shows that the effects were especially prevalent in the lower and mid-high temperatures of our used temperature range. However, the sizes of these effects are small if one uses an established classification of effect sizes, ${ }^{19}$ which states that values below $\varepsilon=0.2$ are small.

\subsection{Results for subgroups}

To further evaluate the observed effects and to get more knowledge about where the effects might stem from, we analysed the effects of the two different lighting situations in various subgroups. In the following sections, the results of the analyses are reported. The descriptive statistics are given in the Appendix.

\subsubsection{Sex}

The whole sample was divided in two equally large sex-subgroups.

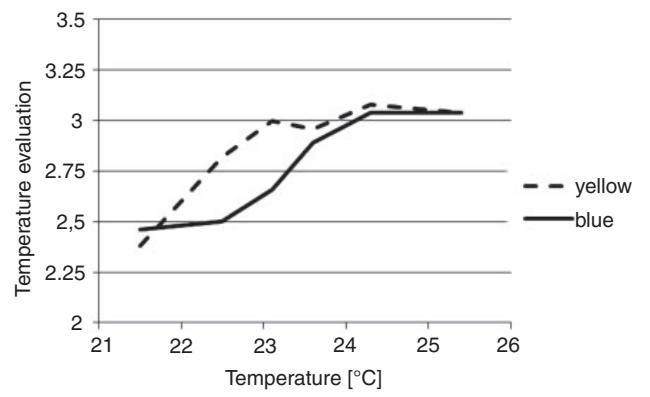

Figure 5 Temperature evaluation as a function of climate (temperature) under yellow and blue light conditions

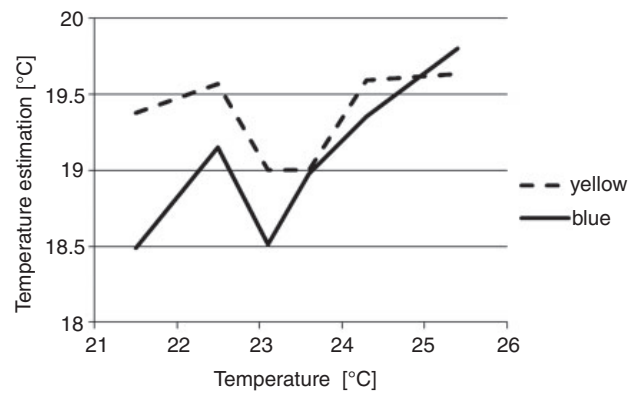

Figure 6 Temperature estimation in degrees Celsius as a function of climate (temperature) under yellow and blue light conditions

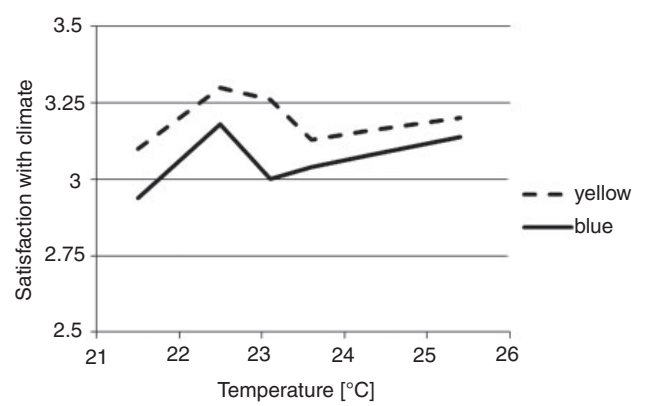

Figure 7 Satisfaction with climate as a function of climate (temperature) under yellow and blue light conditions

In the women subgroup, the effects of yellow light could be observed: The temperature was perceived as higher $\left(F_{(1)}=9.78\right.$, $p<0.05 ; \varepsilon=0.18)$ and this was evaluated as 
Table 3 Descriptive statistics for different variables of evaluation in blue and yellow light and test-results of ANOVAs and effect sizes.

\begin{tabular}{lrrrrrr}
\hline & \multicolumn{1}{c}{$\begin{array}{l}\text { Yellow } \\
M \text { (SD) }\end{array}$} & \multicolumn{1}{c}{$\begin{array}{l}\text { Blue } \\
M \text { (SD) }\end{array}$} & df & \multicolumn{1}{c}{$F$} & $p$ & Effect size $(\varepsilon)$ \\
\hline Temperature perception (1-7) & $3.31(1.1)$ & $3.19(1.1)$ & 1 & 10.6 & 0.001 & 0.14 \\
Temperature evaluation (1-5) & $2.88(1.1)$ & $2.76(1.0)$ & 1 & 10.2 & 0.001 & 0.13 \\
Temperature estimation ( ${ }^{\circ}$ C) & $19.24(2.4)$ & $19.05(2.5)$ & 1 & 8.0 & 0.005 & 0.12 \\
Satisfaction with climate (1-5) & $3.19(0.9)$ & $3.06(0.9)$ & 1 & 10.1 & 0.002 & 0.13 \\
\hline
\end{tabular}

being more comfortable $\left(F_{(1)}=6.23, p<0.05\right.$; $\varepsilon=0.15)$ and the overall satisfaction with the climate was higher in yellow light $\left(F_{(1)}=4.47\right.$, $p<0.05 ; \varepsilon=0.15$ ).

In the male subgroup also three means differed significantly, again with higher means in the yellow light situation: the temperature was evaluated more positively $\left(F_{(1)}=4.10\right.$, $p<0.05 ; \varepsilon=0.12)$, the estimated value in degree Celsius was higher $\left(F_{(1)}=4.71\right.$, $p<0.05 ; \varepsilon=0.13)$ and also the male participants felt more satisfied with the climate situation $\left(F_{(1)}=5.64, p<0.05 ; \varepsilon=0.14\right)$.

Again, we found a pattern in favour of the yellow light but with quite small effect sizes.

\subsubsection{Sensitivity for coldness}

The sample was further divided by the sensitivity for coldness. There were those who were sensitive for coldness and those who were not. In our sample, a majority of $64 \%$ classified themselves as sensitive to coldness.

For the participants with low sensitivity for coldness no significant effects between the blue and yellow light situations could be found. The high-sensitive group felt more satisfied with the climate situation in yellow light $\left(F_{(1)}=6.50, p<0.05 ; \varepsilon=0.17\right)$.

\subsubsection{Sensitivity for heat}

Also, the sample was divided by the sensitivity for heat. Almost half of the subjects in our sample were highly sensitive in this regard $(48.5 \%)$. These subjects did not show any significant differences at all. Those who had low sensitivity for heat showed no significant result for the temperature estimation and two nearly significant mean differences for temperature perception and evaluation $(p=0.06$ and $p=0.08$, respectively). One significant mean difference was found in this subgroup: These participants were more satisfied with the climate situation in yellow light $\left(F_{(1)}=5.64, p<0.05 ; \varepsilon=0.17\right)$.

\subsubsection{Sensitivity for air velocity}

The last division into subgroups was performed by the sensitivity for air velocity, which was either high or low. A majority of $59.3 \%$ classified themselves as sensitive for air velocity.

In contrast to the effects reported before, the low-sensitive minority had a tendency of perceiving the temperature as higher when the cabin was illuminated in blue $(p=0.05)$. And these participants estimated the temperature as being higher in blue light $\left(F_{(1)}=9.14\right.$, $p<0.05 ; \varepsilon=0.23$ ).

The high-sensitive subgroup showed effects in the expected direction, i.e. higher means in yellow cabin light. The perceived temperature was higher $\left(F_{(1)}=10.30, p<0.05 ; \varepsilon=0.22\right)$ as well as the estimation of the temperature $\left(F_{(1)}=6.23, p<0.05 ; \varepsilon=0.21\right)$ and the highsensitive subjects felt more satisfied with the climate in yellow light $\left(F_{(1)}=4.47, p<0.05\right.$; $\varepsilon=0.17)$.

\section{Discussion}

The aim of this study was to analyse the influence of coloured light in an aircraft cabin on the thermal sensations and evaluations of passengers. In a pilot study, in a laboratory, a 
thermal effect of coloured light had been confirmed, ${ }^{9,13}$ and the results of this study in a more realistic environment are positive, too. Specifically, in a certain corridor of temperatures (in the range of roughly $22^{\circ} \mathrm{C}$ to $24.5^{\circ} \mathrm{C}$ ), a main effect of the lighting situation can be observed. The values in this corridor can be seen as typical temperatures one can expect for the climate in real aircraft. Therefore, our results should have relevance for the aviation industry. Subjects tend to have slightly warmer thermal sensations in yellow light and slightly colder sensations in blue light. This comes along with a slightly higher satisfaction with the (whole) climate situation in yellow light.

To get a deeper insight into the factors that might moderate the effects, we had a look at different subgroups. Sex does not obviously play a major role in the 'hue-heat' effect. The results of male and female subjects were comparable. The sensitivity for coldness is a factor, although of minor importance, that seems to moderate the susceptibility for thermal effects, whereas only sensitive people in this regard felt more comfortable with the climate in yellow light.

The sensitivity for heat is a factor that also mildly influences the thermal effects of lighting. Here, low-sensitivity subjects tend to show the effects in the direction of the 'hueheat-hypothesis' and they feel more comfortable in yellow light.

The sensitivity for air velocity plays a bigger role, although not all the mean differences are significant. In these subgroups we observed the most interesting differences in means and in patterns for those who have low sensitivity (they reacted in an unexpected fashion, in favour of blue light) and those who are sensitive for air velocity. These sensitive subjects show (again small) effects in the direction the 'hue-heat hypothesis' postulates. When one considers that these subjects were in the majority of our representative sample, then you have to expect a substantial number of people who might be influenced by the lighting situation with regard to the perception and evaluation of the climate in the cabin of a real airline aircraft.

What do these results mean? We have shown that the 'hue-heat hypothesis' can be corroborated in realistic cabin environments and thus confirmed earlier findings from the laboratory. ${ }^{9}$ It is shown that the "hue-heat hypothesis' is especially valid for sensitive subgroups, mainly for sensitivity to air velocity. The more favourable lighting colour to use seems to be yellow because it contributes, directly or indirectly by means of a kind of 'psychological' warming-up, to the overall satisfaction with the climate.

The rather small impact the coloured lighting has on thermal sensation is in accordance with earlier studies. For example, Fanger et al. ${ }^{6}$ showed a colour effect on temperature sensation of $0.4^{\circ} \mathrm{C}$. Our results also hint at stable thermal effects that are rather small.

Does this all mean that our results are of no practical significance, as Fanger et al. ${ }^{6}$ concluded? We think not. As stated initially, today, energy saving is a topic in industry that is more important than ever before. So we think that even small effects have the potential to lead to vast energy savings: The saving of kerosene for one aircraft by being able to alter the cabin temperature of the air-conditioning to a value only slightly different may be quite small. However, this effect accumulated over many aircraft (from one airline or even manufacturer) may lead to enormous savings of energy and thus money. We think it is especially worthwhile to think about an application as coloured light could be implemented easily in aircraft of the upcoming generation.

Finally, our findings indicate that the colour of lighting is an objective factor that has an influence on subjective well-being, especially for susceptible persons. Future 
models of thermal comfort should integrate this objective factor.

Further studies might help to generate more precise ideas about the nature and extent of these effects and the intra- and extra-personal circumstances that facilitate or promote them. Also, it would be interesting to know if there was another pattern of results if our studies were repeated in a pressurized aircraft in real flight. Furthermore, our experiments simulated a short-haul flight. Future studies should also include the simulation of long-haul flights or more specifically longer exposure times to certain lighting situations. With such experiments any long-term effects the lighting might have (adaptation, frustration, etc.) could be examined. Finally, on the more technical side, experiments or theoretical computations should clarify how much energy and costs are saved in applying the 'hue-heat' effect in certain industrial environments, like in large or small airlines and by aircraft manufacturers.

\section{Funding}

The study was supported by the Bundesministerium für Bildung und Forschung [grant number 03CL08].

\section{Acknowledgements}

The authors would like to thank their colleagues at the Institute of Aerodynamics and Flow Technology at the German Aerospace Center (DLR) for their cooperation in the experiments and data processing.

\section{References}

1 Heijs W, Stringer P. Research on residential thermal comfort: Some contributions from environmental psychology. Journal of Environmental Psychology 1988; 8: 235-247.
2 Advisory Council for Aeronautics Research in Europe. Strategic Research Agenda Volume 1. ACARE, 2002.

3 Lüdders HP, Strummel H, Thielecke F. Model-based development of multifunctional fuel cell systems for more-electric-aircraft. CEAS Aeronautical Journal 2013; 4: 151-174.

4 Berry PC. Effect of colored illumination upon perceived temperature. Journal of Applied Psychology 1961; 45: 248-250.

5 Green TC, Bell PA. Additional considerations concerning the effects of 'warm' and 'cool' wall colours on energy conservation. Ergonomics 1980; 23: 949-954.

6 Fanger P, Breum N, Jerking E. Can colour and noise influence man's thermal comfort?

Ergonomics 1977; 20: 11-18.

7 Hoheisel H. The evolution to modern jet engines. In: Hirschel EH, Prem H, Madelung G. (eds) Aeronautical Research in Germany-from Lilienthal until Today.

Berlin: Springer, 2004, pp. 407-430.

8 Hoheisel H, von Geyr H Frhr. The influence of engine thrust behaviour on the aerodynamics of engine airframe integration. CEAS Aeronautical Journal 2012; 3: 79-92.

9 Winzen J, Albers F, Marggraf-Micheel C. The influence of coloured light in the aircraft cabin on passenger thermal comfort. Lighting Research and Technology. First published 13 June 2013; DOI: 10.1177/1477153513484028.

10 Quehl J. Comfort Studies on Aircraft Interior Sound and Vibrations. Aachen: Shaker, 2001.

11 De Dear R, Brager GS. Developing an Adaptive Model of Thermal Comfort and Preference. UC Berkeley, USA: Center for Environmental Design Research, 1998.

12 Richards LG. On the psychology of passenger comfort. In: Osborne DJ, Levis, JA. (eds) Human Factors in Transport Research: 2. Waltham: Academic Press, 1980, pp. 15-23.

13 Marggraf-Micheel C, Winzen J, Albers F. Klimaempfinden und Komfort in der Flugzeugkabine moderiert durch farbiges Licht?! - Ergebnisse einer Studie aus dem Projekt LiKab. [Sensation of climate and comfort in the aircraft cabin moderated by coloured light?! - Results from a study in the LiKab-project]. Tagungsband 60. Deutscher Luft- und Raumfahrtkongress [Proceedings of 
the $60^{\text {th }}$ German Congress on Aviation and Aerospace]. Bremen: DGLR, 2011.

14 Comité Européen de Normalisation. DIN EN 4618 Aerospace Series - Aircraft Internal Air Quality Standards, Criteria and Determination Methods. Brussels: CEN, 2009.

15 Steyer R, Schwenkmezger P, Notz P, Eid M. Der Mehrdimensionale Befindlichkeitsfragebogen (MDBF). Handanweisung [A Multidimensional Questionnaire for Subjective Well-being $(M D B F)$. Manual]. Göttingen, Germany: Hogrefe, 1997.

16 Frank R. FAW-Fragebogen zur Erfassung des aktuellen körperlichen Wohlbefindens [FAWQuestionnaire to assess current physiological well-being]. In: Schumacher J, Klaiberg A, Brähler E. (eds) Diagnostische Verfahren zu Lebensqualität und Wohlbefinden [Diagnostic Instruments for the Assessment of Life Quality and Well-being]. Göttingen, Germany: Hogrefe, 2003, pp. 116-121.
17 Rammstedt B, John OP. Kurzversion des Big Five Inventory (BFI-K): Entwicklung und Validierung eines ökonomischen Inventars zur Erfassung der fünf Faktoren der Persönlichkeit [Short version of the Big Five Inventory (BFI$\mathrm{K})$ : Development and validation of an economical inventory for the assessment of the five factors of personality]. Diagnostica 2005; 51: 195-206.

18 Marggraf-Micheel C, Rütten M, Piewald C. Thermal comfort in the aircraft cabin: The potential of objective and subjective measurement. In: Proceedings of CEAS 2009 European Air and Space Conference. CEAS 2009

European Air and Space Conference. 26-29 October. Manchester, UK.

19 Cohen J. Statistical Power Analysis for the Behavioral Sciences. 2nd Edition, Hillsdale, NJ: Lawrence Erlbaum Associates, 1988. 


\section{F Albers et al.}

\section{Appendix}

Descriptive statistics for different variables of evaluation in blue and yellow light for subgroups

\begin{tabular}{|c|c|c|c|c|}
\hline & \multicolumn{4}{|l|}{ Sex } \\
\hline & \multicolumn{2}{|l|}{ Female } & \multicolumn{2}{|l|}{ Male } \\
\hline & Yellow $M(\mathrm{SD})$ & Blue $M(\mathrm{SD})$ & Yellow $M(\mathrm{SD})$ & Blue $M(\mathrm{SD})$ \\
\hline Temperature perception (1-7) & $2.97(1.2)$ & $2.82(1.1)$ & $3.63(1.0)$ & $3.55(1.0)$ \\
\hline Temperature evaluation (1-5) & $2.53(1.0)$ & $2.41(1.0)$ & $3.21(1.0)$ & $3.11(0.9)$ \\
\hline Temperature estimation $\left({ }^{\circ} \mathrm{C}\right)$ & $18.99(2.6)$ & $18.82(2.5)$ & $19.46(2.1)$ & $19.25(2.4)$ \\
\hline \multirow[t]{4}{*}{ Satisfaction with climate $(1-5)$} & $2.98(0.8)$ & $2.86(0.9)$ & $3.39(0.9)$ & $3.26(0.9)$ \\
\hline & \multicolumn{4}{|c|}{ Sensitivity for coldness } \\
\hline & \multicolumn{2}{|c|}{ High coldness sensitivity } & \multicolumn{2}{|c|}{ Low coldness sensitivity } \\
\hline & Yellow $M(\mathrm{SD})$ & Blue $M(\mathrm{SD})$ & Yellow $M(\mathrm{SD})$ & Blue $M(\mathrm{SD})$ \\
\hline Temperature perception (1-7) & $3.08(1.1)$ & $2.98(1.1)$ & $3.75(0.9)$ & $3.76(1.0)$ \\
\hline Temperature evaluation (1-5) & $2.58(1.0)$ & $2.56(1.0)$ & $3.31(0.9)$ & $3.32(0.9)$ \\
\hline Temperature estimation $\left({ }^{\circ} \mathrm{C}\right)$ & $19.03(2.5)$ & $19.04(2.4)$ & $19.47(2.4)$ & $19.31(2.6)$ \\
\hline \multirow[t]{4}{*}{ Satisfaction with climate $(1-5)$} & $2.99(0.8)$ & $2.84(0.9)$ & $3.39(0.9)$ & $3.36(0.9)$ \\
\hline & \multicolumn{4}{|c|}{ Sensitivity for heat } \\
\hline & \multicolumn{2}{|c|}{ High heat sensitivity } & \multicolumn{2}{|c|}{ Low heat sensitivity } \\
\hline & Yellow $M(\mathrm{SD})$ & Blue $M(\mathrm{SD})$ & Yellow $M(\mathrm{SD})$ & Blue $M(\mathrm{SD})$ \\
\hline Temperature perception (1-7) & $3.38(1.0)$ & $3.40(1.1)$ & $3.29(1.1)$ & $3.16(1.1)$ \\
\hline Temperature evaluation (1-5) & $2.90(1.0)$ & $3.00(1.1)$ & $2.82(1.0)$ & $2.71(0.9)$ \\
\hline Temperature estimation $\left({ }^{\circ} \mathrm{C}\right)$ & $19.07(2.8)$ & $19.16(2.6)$ & $19.34(2.2)$ & $19.12(2.6)$ \\
\hline \multirow[t]{4}{*}{ Satisfaction with climate $(1-5)$} & $3.20(0.9)$ & $3.16(0.8)$ & $3.09(0.9)$ & $2.92(1.0)$ \\
\hline & \multicolumn{4}{|c|}{ Sensitivity for air velocity } \\
\hline & \multicolumn{2}{|c|}{ High air velocity sensitivity } & \multicolumn{2}{|c|}{ Low air velocity sensitivity } \\
\hline & Yellow $M(\mathrm{SD})$ & Blue $M(\mathrm{SD})$ & Yellow $M(\mathrm{SD})$ & Blue $M(\mathrm{SD})$ \\
\hline Temperature perception (1-7) & $3.21(1.1)$ & $3.02(1.1)$ & $3.49(0.9)$ & $3.62(1.0)$ \\
\hline Temperature evaluation (1-5) & $2.62(1.0)$ & $2.59(1.0)$ & $3.16(1.0)$ & $3.20(1.0)$ \\
\hline Temperature estimation $\left({ }^{\circ} \mathrm{C}\right)$ & $19.28(2.6)$ & $18.90(2.7)$ & $19.11(2.4)$ & $19.45(2.4)$ \\
\hline Satisfaction with climate (1-5) & $3.03(0.9)$ & $2.85(0.9)$ & $3.29(0.8)$ & $3.28(0.8)$ \\
\hline
\end{tabular}

